\title{
Preparation and Evaluation of Combination Tablets of Diclofenac Sodium and Antacid Mixture
}

\author{
Jannatul Fardous, Faria Farzana Perveen, Md Zahidul Islam, A. H. M. Saifuddin*, Sakina Sultana \\ Department of Pharmacy, Jahangirnagar University, Savar, Dhaka, Bangladesh
}

Email address:

ahm.saifuddin11@gmail.com (A. H. M. Saifuddin)

${ }^{*}$ Corresponding author

\section{To cite this article:}

Jannatul Fardous, Faria Farzana Perveen, Md Zahidul Islam, A. H. M. Saifuddin, Sakina Sultana. Preparation and Evaluation of Combination Tablets of Diclofenac Sodium and Antacid Mixture. Journal of Drug Design and Medicinal Chemistry. Vol. 3, No. 5, 2017 , pp. 67-70. doi: 10.11648/j.jddmc.20170305.11

Received: July 28, 2016; Accepted: February 22, 2017; Published: October 31, 2017

\begin{abstract}
In this present study combination tablets containing diclofenac sodium, dried aluminium hydroxide gel and magnesium trisilicate were prepared using customized formula and common properties of tablets like hardness, thickness, diameter, weight and disintegration time along with the flow properties of granules were determined. Our results showed that most properties of the tablets complied with the official limit of acceptance. The $\mathrm{pH}$, water absorption index, dissolution behavior and organoleptic property of tablets were also checked. Results showed that $\mathrm{pH}$ of combination tablets was $8.27 \pm$ 0.04 when dissolved in purified water. Water absorption index varied from $0.1 \%$ to $0.2 \%$. Tablets were undergone dissolution by $85 \%$ and $96 \%$ in 45 and 90 minutes respectively. In the study the organoleptic properties of the tablets remained the same over a period of 60 days.
\end{abstract}

Keywords: Diclofenac Sodium, Dried Aluminium Hydroxide Gel, Magnesium Trisilicate, Organoleptic Property and Combination Tablets

\section{Introduction}

In recent era non steroidal anti-inflammatory drugs (NSAIDs) have received great attention in treating inflammation and combating pain resulting from cellular damage caused by mechanical injury and infection. The main reason behind such attention is that NSAIDs are devoid of narcotic effects produced by the narcotic analgesics and hence these are called non-narcotic analgesics [1]. The common NSAIDs available in the market are salicylates, ibuprofen, naproxen and diclofenac and among these drugs diclofenac sodium might be the most commonly prescribed NSAID in Bangladesh [2]. At present the number of pharmaceutical companies in Bangladesh is around 260 and a large number of these companies prepare diclofenac sodium in different dosage forms. The commonly available dosage forms containing diclofenac sodium are 'tablets', 'suppositories' and 'gel' [2]. Characteristically diclofenac sodium is a salt of [2-(2, 6-dichlorophenyl) amino] benzene acetic acid] [3]. Other salt form of this acid that is commercially available is diclofenac potassium but the sodium salt perhaps is the better choice because of its stability, pleasant taste and odor. Secondly, this drug offers a wide range of versatility in uses. And most importantly this drug shows better and stronger anti-inflammatory action than paracetamol, indomethacin and other NSAIDs. It is reported that diclofenac sodium being a salt of an organic acid has the tendency to get accumulated non-specifically at the sites of inflammation. Such phenomenon in turn reduces intracellular concentration of free arachidonic acid either by altering the release or uptake of the acid and ultimately strengthens drug action [1]. Moreover, this drug is also found to be suitable to manage and control for long term symptomatic treatment of rheumatoid arthritis, as well as short term treatment of acute myolo-skeletal injury, post operative pain and dysmenorrhoea. Although this is a drug of choice but this agent shows side effects and some might be potential. For instances diclofenac sodium in GIT induces irritation, bleeding, ulceration and eventually wall perfusion $[1,2,3]$. Therefore, patients are strongly advised to take anti acidic preparations along with this drug. Bangladesh is a high densely populated country and the number of physicians is relatively low. As a result the ratio between physician and patient is far behind the international requirements. According to the report of Bureau of Statistics, 2003 here one physician spends less than a minute for counseling a patient 
[4]. So it is not unlikely that dichlofenac sodium is prescribed without any acid controlling agents. A patient may forget to take an antacid preparation during diclofenac therapy which may end up with serious physiological complication (s) [1].

The objective of this study was to formulate tablets containing diclofenac sodium and antacid mixture (dried aluminium hydroxide gel and magnesium trisilicate) with the hope that such a combination tablet would open a new era to manage NSAID induced complications. Here diclofenac sodium was given preferences as it was and still is a tool of research interest [5,6] and formulations containing aluminium hydroxide gel and magnesium trisilicate are still the most popular form of antacids known to the common people $[7,8]$. To the best knowledge and awareness of the authors such tablets containing diclofenac sodium and antacid mixture has not been carried out before.

\section{Materials and Methods}

\subsection{Materials}

Diclofenac sodium, aluminium hydroxide gel, magnesium trisilicate, polyvinylpyrrolidones, lactose, starch, magnesium stearate, methyl and propyl parabens and benzoates were obtained from the departmental laboratory, Jahangirnagar University. Diclofenac sodium was a gift from Square Pharmaceutical Ltd, Bangladesh.

\subsection{Methodologies}

In the study three sets of tablets (Control set-1, Control set-2 and combination tablets) were prepared. Each set comprising of 40 tablets. The sets were designated as combination tablets (containing diclofenac sodium and antacid mixture (more specifically a mixture of aluminium hydroxide gel and magnesium trisilicate)), control set-1 (containing diclofenac sodium only) and lastly control set-2 (containing antacid mixture only). Here tablets were prepared following wet granulation method as described by Banker and Anderson, Enever and Talman [7,9,10].

After preparing the tablets were primarily doubly wrapped in small bags made up of polyethylene sheet (thickness $>20$ micron) and then were kept in an air tight container under normal storage condition until required for further evaluation.

\subsection{Property Evaluation}

In the study the flow property of tablet granules was first determined in terms of Carr's index and Hausner ratio following the processes as described by Aulton [8]. Tablets diameter and thickness were measured with the help of a slide calipers. Monsanto hardness tester (Campbell electronics, India) calibrated in $\mathrm{kg} / \mathrm{cm}^{2}$ was used for measuring crushing strength of tablets. For measuring friability and weight of tablets, a friabilator (Campbell electronics, India) and a four digit electronic balance were used respectively. Disintegration times of the tablets were determined using six bucket disintegrator (Campbell electronics, India) and $\mathrm{pH}$ of tablets was determined using a $\mathrm{pH}$ meter (Hanna instruments, $\mathrm{pH} 300$ ). In every respect the processes followed were according to Banker and Anderson, Travers and Allen et al [7, 11, 12].

For determining the dissolution profile of tablets a single bucket dissolution apparatus (Apparatus-1) was used [13] where dissolution media was phosphate buffer at $\mathrm{pH} 7.5$. Here percentage of drug release was quantified with the help of a standard calibration curve. The curve was drawn with known concentration values ranging from 1 to $40 \mu \mathrm{g} / \mathrm{ml}$. The absorbance of drug was measured using UV-visible spectrophotometer (UV-1601 PC, Shimadzu, Japan) at $\lambda_{\max }$ $235 \mathrm{~nm}$ and the unknown concentration was calculated from the calibration curve using straight line equation with $\mathrm{r}^{2}$ value $>0.995$.

In the present study WAI (water absorption index) was determined following a process where a pre-weighed tablet was taken on a tissue paper (folded by six times). Then water was added drop wise to the tablet until the tissue paper lying under became just wet. At this point addition of water was stopped and the tablet was reweighed. Here gain in weight was due to water absorption and that was calculated out and was expressed in terms of percentage of weight gain.

The organoleptic properties of tablets were checked over a period of two months. Six human volunteers of age ranging between 18-22 years (irrespective of gender) participated in the test. They inspected the tablet deformation (if any, caused by chipping, picking and surface grittiness) visually. Their comments were later on expressed according to the typical thermometer scale used for consumer products [14].

\section{Results and Discussion}

This study was conducted for the preparation and quality evaluation of combination tablets containing diclofenac sodium and a mixture of aluminium hydroxide gel and magnesium trisilicate. Data obtained from the combination tablets were compared with the tablets of control groups. The results have been shown in tables 1 to 3 and figure 1 .

Table 1 represents the flow properties of tablet granules of different groups. Carr's index and Hausner ratio are two major determinants of flow property. According to Carr's index, value between 15-25 signifies good flow, whereas when Hausner ratio is $<1.25$ it suggests good flow properties [8]. In our study Carr's index and Hausner ratio for both the values were indicative of good flow of granules of all formulations (table 1).

Table 1. Flow property of granules.

\begin{tabular}{llll}
\hline \multirow{2}{*}{ Determinants } & \multicolumn{4}{c}{ Flow property of granules of formulations } \\
\cline { 2 - 4 } & Control set-1 & Control set-2 & Combination tablets \\
\hline Carr's Index (\%) & 15.23 & 19.55 & 18.76 \\
Hausner Ratio & 1.18 & 1.24 & 1.23 \\
\hline
\end{tabular}

Control set-1 represents tablet containing diclofenac sodium only Control set-2 represents tablets containing antacid mixture only

Combination tablets represent tablets containing diclofenac sodium and antacid mixture

Table 2 represents the physical properties of three formulations. Among all the properties thickness, diameter, hardness (in terms of crushing strength), friability and content uniformity were given the preferences. 
Table 2. Properties of tablets of three formulations.

\begin{tabular}{lllll}
\hline Property of tablets & Control set- 1 & Control set- 2 & Combination tablets & Official limit of acceptance \\
\hline Thickness $(\mathrm{cm}), \mathrm{n}=10$ & $0.36 \pm 0.01$ & $0.31 \pm 0.00$ & $0.68 \pm 0.04$ & \pm 5 \\
Diameter $(\mathrm{cm}), \mathrm{n}=10$ & $1.180 \pm 0.01$ & $1.02 \pm 0.00$ & $1.184 \pm 0.01$ & NOS \\
Crushing strength $\left(\mathrm{kg} / \mathrm{cm}^{2}\right), \mathrm{n}=10$ & $1.5 \pm 0.50$ & $1.19 \pm 0.08$ & $2.5 \pm 0.50$ & $\geq 4$ \\
Friability, $\mathrm{n}=10$ & ND & ND & 2.24 & $<1 \%$ \\
Net content weight $(\mathrm{mg}), \mathrm{n}=10$ & $431.45 \pm 10.06$ & $420.73 \pm 0.08$ & $886.20 \pm 5.30$ & \pm 5 \\
Disintegration time $(\mathrm{min}), \mathrm{n}=6$ & 3.33 & 10.50 & 5.17 & $5-30$ \\
$\mathrm{pH}, \mathrm{n}=4$ & $7.01 \pm 0.04$ & $8.70 \pm 0.17$ & $8.27 \pm 0.04$ & NOS \\
WAI $(\%), \mathrm{n}=6$ & ND & ND & $0.12 \pm 0.03$ & NOS \\
\hline
\end{tabular}

$\mathrm{ND}=$ Not done

NOS $=$ No official specification available

Values are given in mean \pm SD where $\mathrm{n}$ represents the number of samples under investigation

Tablet thickness and diameter are two major determinants of physical properties of tablets. These parameters imposes shape uniformity and hence product elegance. Any visibly discernible defect puts product acceptance under criticism. Again, any deformation in tablet shape and size creates problem (s) in packaging as well [7, s11]. Therefore, it was expected that the tablets of three groups would be uniform in size, shape and thickness and in case of variation limit is $\pm 5 \%$ [7]. Our study results showed that the variation in each tablet group was within the limit of acceptance (table 3 ).

The hardness of tablets exhibits integrity of tablets against an externally applied load tending to cause deformation and breaking of tablets [11]. For control set-1 tablet hardness was $1.5 \pm 0.50 \mathrm{~kg} / \mathrm{cm}^{2}$ and for tablets of control set- 2 and combination tablets the hardness were $1.19 \pm 0.08$ and $2.50 \pm$ $0.50 \mathrm{~kg} / \mathrm{cm}^{2}$ respectively. Here, none of the values complied with the recommended official value as stated by Allen et al [12]. According to Allen et al [12] tablets should withstand crushing load of at least $4 \mathrm{~kg}$ without undergoing any structural deformation. Our study failed to follow the recommended value. Such results were not the same as was expected (table 2). This needs further exploration bearing in mind that tablet hardness is not an absolute property indicator of tablet strength [7].

Friability is a measure of release of drug from the tablet surface during transportation and handling due to abrasion. Ideally it is an another indicator of tablet hardness. According to Allen et al [12] friability should be less than $1 \%$ and friability may deviate from the official value due to many reasons. It could be due to the use of faulty die-punch assembly or could be due to the use of either wet granules or super dried granules [7]. For good quality granules, the recommended moisture content level is between $2-4 \%$ [7]. Here, friability of combination tablets was $2.24 \%$ (table 2) which was not in general agreement with the recommended value.

Disintegration time is another important parameter for tablets. It shows the time required for a tablet to be disintegrated in an ambient fluid. Thus, this step has become a prerequisite for dissolution process which is an important determinant for bioavailability. In the present study disintegration was performed in distilled water. Disintegration time for combination tablets was found to be 5.17 minutes; while the disintegration time for tablets of control set-1 and control set-2 were 3.33 minutes and 10.50 minutes respectively (table 2). Our results complied with the official limit of acceptance [12, 13]. Similar was the cases with net content weight of tablets of three groups.

It was mentioned earlier that our aim was to combat gastric acidity that might have been produced due to the continuous use of diclofenac sodium based oral preparations. In the present study it was expected that the use of combination tablets may pacify gastric acidity in-vivo as antacid mixture was one of the major components. So the $\mathrm{pH}$ of the combination tablets (in distilled water) was determined. Results are shown in table 2. The $\mathrm{pH}$ was found to be $8.27 \pm 0.4$, while $\mathrm{pH}$ of tablets containing only diclofenac sodium in the same was $7.01 \pm 0.04$ and that of antacid tablets was $8.7 \pm 0.17$. Such results are in favor of meeting our study.

In combination tablets, antacid mixture of aluminium hydroxide gel and magnesium trisilicate was present and moisture absorption was not unlikely. In the study therefore \%WAI was calculated out and value ranged from 0.1 to $0.2 \%$ (figures have been rounded off) (table 2) which supported that tablets were not highly moisture sensitive in the presence of antacids.

Dissolution is a process that shows the time taken by the tablets to be in solutions. Once a tablet is taken orally, it should be rapidly dissolved into the gastric fluid. As a rule of thumb, rapid dissolution promotes absorption and hence results rapid bioavailability [15]. In the present study the dissolution time studies was determined for combination tablets $(n=2)$ and our results showed that in 45 minutes the combination tablets undergone dissolution by $85 \%$ and in 90 minutes the combination tablets undergone dissolution by $96 \%$ (figure 1). Such trend was in line with the Pharmacopeial value [16].

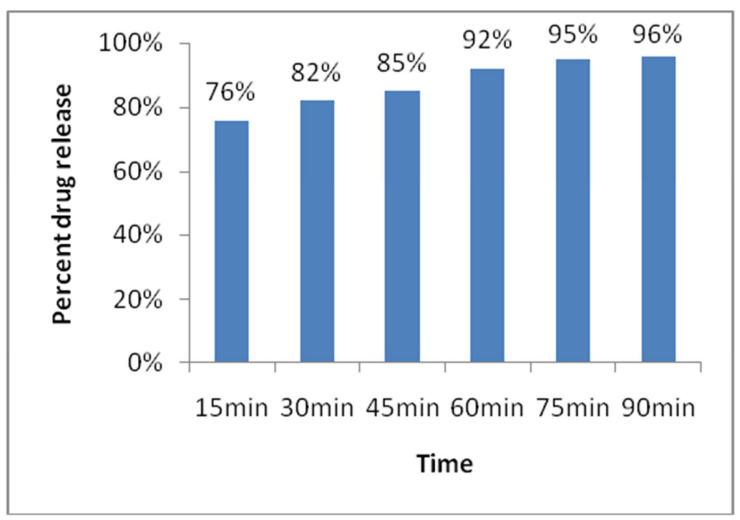

Figure 1. Dissolution pattern of combination tablets. 
Organoleptic property meaning the property that can be perceived by sense organs serves as a primary investigational tool for property evaluation. For combination tablets such study was conducted and results are shown in table 3 . It shows that the properties remained the same over a period of 60 days under normal conditions.

Table 3. Organoleptic properties of combination tablets.

\begin{tabular}{lllll}
\hline $\begin{array}{l}\text { Organoleptic } \\
\text { properties }\end{array}$ & Day 1 & Day 30 & Day 60 & Comment \\
\hline Chipping & Negligible & Negligible & Negligible & Acceptable \\
Picking + Sticking & Not seen & Not seen & Not seen & Good \\
Any crack & Not seen & Not seen & Not seen & Good \\
Surface smoothness & Not seen & Not seen & Not seen & Good \\
\hline
\end{tabular}

\section{Conclusion}

Thus it can be concluded that formulation and manufacture of combination tablets based on a mixture of diclofenac sodium and antacid is possible with success.

\section{Acknowledgements}

Authors would like to acknowledge Department of Pharmacy, Jahangirnagar University, Bangladesh for providing necessary equipments and ingredients. Special thanks to Square Pharmaceutical Ltd, Bangladesh for proving diclofenac sodium.

\section{References}

[1] Insel, P. A. (1996). In: Goodman \& Gilman's The Pharmacological Basis of Therapeutics (Hardman, J. G., Limbird, L. E., Molinoff, P. B., Ruddon, R. W. and Gilman, A. G., Eds.), McGraw -Hill, New York. pp 618, 637.

[2] Shahidi, R. U. (2015). In: QUIMP-17. Katabon Central Mosque Campus, Dhaka. pp. 334, 338, 561-562.

[3] Robert, B. F. (2005). In: Remington-The Science and Practice of Pharmacy (Henrickson, R., Ed.), Lippincott Williams and Wilkins, Philadelphia. Chapter 83, Analgesic, Antipyretic and Anti-inflammoatory drugs. pp. 1536.

[4] Bangladesh Beaurue of Statistics (2003). Statistical Pocket book-Bangladesh. pp. 367-369
[5] Pfaffenrath, V and Scherzer, S. (1995). Analgesics and NSAIDs in the treatment of acute migraine attack. Cephalalgia. Suppl 15, 14-20.

[6] Terhagg, B., Hoffman, A., Barkworth, M and Vens, C. B. (2000). Bioavailability of a new effervescent tablet of diclofenac. Int J Clin Pharmacol Ther. 38, 546-551.

[7] Banker, G. B and Anderson, N. R. (1987). In: The Theory and Practice of Industrial Pharmacy (Lachmann, L., Lieberman, H. A. and Kanig, J. L., Eds.), Lea and Febiger, Philadelphia, Chapter 11, Tablets, pp. 293-294, 296, 299, 311-314, 320, 343.

[8] Aulton, M. E. (2013). Aulton's Pharmaceutics. The design and manufacture of medicines Churchill, Livingstone, Edinburgh. Chapter 12, Powder flow, pp. 194, 195

[9] Enever, R. P. (2004). In: Bentley's Textbook of Pharmaceutics (Rawlin, E. A., Ed.), Bailliere Tindall, London. Chapter 10, Drug stability, pp. 140-142, 146-147.

[10] Talman, F. A. J. (2004). In: Bentley's Textbook of Pharmaceutics (Rawlin, E. A., Ed.), Bailliere Tindall, London. Chapter 19, Tablets and Capsules, pp. 275.

[11] Travers, D. N. (1986). In: Cooper and Gunn's Tutorial Pharmacy (Carter, S. J., Ed.), Chaper 19, Powder flow and Compaction. pp 222-223.

[12] Allen, L. V (jr)., Popovich, N. G. and Ansel, H. C. (2011). Ansel's Pharmaceutical Dosageforms and Drug delivery system. Lippincott Williams and Wilkins, Philadelphia. Chapter 8, Tablets, pp. 233, 236, 238-239

[13] British Pharmacopoiea (1988). pp 893, 895.

[14] Bolton, S. (1987). In: The Theory and Practice of Industrial Pharmacy (Lachmann, L., Lieberman, H. A. and Kanig, J. L., Eds.), Lea and Febiger, Philadelphia, Chapter 10, Statistical applications in the pharmaceutical sciences. pp. 266.

[15] Shargel, L and Yu, A. B. C. (1993). In: Applied Biopharmaceutics and Pharmacokinetics. Chapter 8. Biopharmaceutic consideration in drug product design. Prentice Hall International Inc. USA. pp. 137-140, 151-152.

[16] The United States Pharmacopeia XX/ National Formulary XV. (1982). Supplement 3. U.S. Pharmacopeial Convention, Rockville, MD. pp 310. 